\title{
Determinants of methicillin-susceptible Staphylococcus aureus native bone and joint infection treatment failure: a retrospective cohort study
}

\author{
Florent Valour ${ }^{1,2^{*}}$, Anissa Bouaziz ${ }^{1}$, Judith Karsenty ${ }^{1}$, Florence Ader ${ }^{1,2}$, Sébastien Lustig ${ }^{2,3}$, Frédéric Laurent ${ }^{2,4}$,
} Christian Chidiac $^{1,2}$, Tristan Ferry ${ }^{1,2}$ and on behalf of the Lyon BJI study group

\begin{abstract}
Background: Although methicillin-susceptible Staphylococcus aureus (MSSA) native bone and joint infection (BJI) constitutes the more frequent clinical entity of BJl, prognostic studies mostly focused on methicillin-resistant $S$. aureus prosthetic joint infection. We aimed to assess the determinants of native MSSA BJ outcomes.

Methods: Retrospective cohort study (2001-2011) of patients admitted in a reference hospital centre for native MSSA BJI. Treatment failure determinants were assessed using Kaplan-Meier curves and binary logistic regression.

Results: Sixty-six patients (42 males [63.6\%]; median age 61.2 years; interquartile range [IQR] 45.9-71.9) presented an acute $(n=38 ; 57.6 \%)$ or chronic $(n=28 ; 42.4 \%)$ native MSSA arthritis $(n=15 ; 22.7 \%)$, osteomyelitis ( $n=19$; $28.8 \%$ ) or spondylodiscitis ( $n=32 ; 48.5 \%)$, considered as "difficult-to-treat" in 61 cases (92.4\%). All received a prolonged (27.1 weeks; IQR, 16.9-36.1) combined antimicrobial therapy, after surgical management in 37 cases (56.1\%). Sixteen treatment failures (24.2\%) were observed during a median follow-up period of 63.3 weeks (IQR, 44.7-103.1), including 13 persisting infections, 1 relapse after treatment disruption, and 2 super-infections. Independent determinants of treatment failure were the existence of a sinus tract (odds ratio [OR], 5.300; 95\% confidence interval $[\mathrm{Cl}], 1.166-24.103)$ and a prolonged delay to infectious disease specialist referral (OR, 1.134; 95\% Cl 1.013-1.271).

Conclusions: The important treatment failure rate pinpointed the difficulty of cure encountered in complicated native MSSA BJI. An early infectious disease specialist referral is essential, especially in debilitated patients or in presence of sinus tract.
\end{abstract}

Keywords: Staphylococcus aureus, Bone and joint infection, Treatment failure

\section{Background}

Bone and joint infections (BJIs) constitute difficult-totreat clinical entities, known to be associated to significant morbidity and mortality rates. Most of the current literature on BJI concerns orthopaedic device infections and/or methicillin-resistant Staphylococcus aureus (MRSA). However, native infections represent the most frequent

\footnotetext{
* Correspondence: florent.valour@chu-lyon.fr

${ }^{1}$ Service des maladies infectieuses et tropicales, Hospices Civils de Lyon, Groupement Hospitalier Nord, Lyon, France

${ }^{2}$ Université Claude Bernard Lyon 1, INSERM U1111, International Centre for Research in Infectious diseases, Lyon, France

Full list of author information is available at the end of the article
}

clinical form of BJI, accounting for approximately $70 \%$ of cases, and are mainly caused by methicillin-susceptible Staphylococcus aureus (MSSA) [1]. With a respective incidence of 4-10, 10 and 2.4 per 100,000 person-year, septic arthritis, osteomyelitis and vertebral osteomyelitis are associated with a mortality rate of $2-10 \%$, and a risk of permanent loss of joint function of $40 \%$ [2,3]. It has recently been shown that the setting of a systematic infectious disease specialist consultation in a septic orthopaedic surgery unit allows a better adjustment of empirical antimicrobial therapy [4]. However, risk factors for treatment failure have 
poorly been studied. We addressed this question in a retrospective cohort study.

\section{Methods}

All patients with native MSSA BJI were enrolled in a monocentric retrospective cohort study (2001-2011) in the reference center for the management of complex BJI of the Lyon University Hospitals, France. To be included, patients should present clinical evidences of infection and at least one reliable bacteriological sample positive for MSSA including percutaneous joint fluid aspiration, surgical sample, and/or blood culture, excluding patients with diabetic foot- and decubitus ulcer-related BJI because of the specific management of these infections. The time from initiation of symptoms of infection to diagnosis defined acute (infection lasting for $\leq 4$ weeks) and chronic (infection lasting for $>4$ weeks) infections [5]. The modified Charlson comorbidity index was calculated as previously described [6]. Immunosuppression was defined as: i) steroid therapy $>10 \mathrm{mg}$ of prednisone per day or equivalent; ii) immunosuppressive drug during the two last months before BJI onset; or iii) chemotherapy. Treatment failure included i) persisting infection under appropriate antimicrobial therapy; and/or ii) relapse after antimicrobial therapy disruption.

Data were collected from medical records, nursing charts and biological software in an anonymous standardized case report form. Frequencies of the study variables were described as effectives (\%) for dichotomous variables, and medians (interquartile range [IQR]) for continuous values. For the percentage calculation of each variable, the number of missing values was excluded from the denominator. Non-parametric statistical methods were used to compare the study groups (Khi2, Fisher exact test, MannWhitney U test), as appropriate. Kaplan-Meier curves were compared between groups using the log-rank test. Stepwise binary logistic regression was used to determine risk factors for treatment failure. After checking variables for interactions, variables with medical meaning and $\mathrm{p}$ values obtained in univariate analysis $<0.15$ were included in the final multivariate model. A value of $\mathrm{p}<0.05$ was taken as significant. All analyses were performed using SPSS software version 17.0 (SPSS, Chicago, IL).

This study received the approval of the French SouthEast ethics committee with the reference number CAL2011-21. In accordance with the French legislation, written informed patient consent was not required for any part of the study.

\section{Results}

After exclusion of 4 diabetic foot- or decubitus ulcerrelated infections and 7 patients with numerous missing values, 66 patients were enrolled in the analysis (42 males; $63.6 \%$ ), with a median age of 61.2 years (IQR, 45.9-71.9).
Demographic characteristics, comorbidities and BJI presentation are summarized in Table 1. Of note, 61 (92.4\%) of included BJI were considered as difficult-to-treat, including chronic BJI $(\mathrm{n}=28 ; 42.4 \%)$, local abscess $(\mathrm{n}=33$; $50.0 \%)$, sinus tract $(\mathrm{n}=18 ; 27.3 \%)$, bacteraemia $(\mathrm{n}=35$; $53.0 \%)$ and/or associated infective endocarditis $(\mathrm{n}=4$; 6.1\%). Importantly, in comparison with arthritis, osteomyelitis were more often chronic $(\mathrm{n}=16(84.2 \%)$ versus $\left.\mathrm{n}=2(13.3 \%) ; \mathrm{p}<10^{-3}\right)$, and sinus tract $(\mathrm{n}=13(68.4 \%)$ versus $\mathrm{n}=2(13.3 \%) ; \mathrm{p}=0.002)$ and abscesses $(\mathrm{n}=10$ $(52.6 \%)$ versus $\mathrm{n}=2(13.3 \%) ; \mathrm{p}=0.030)$ were more frequent.

A surgical management was performed in 37 cases (56.1\%). All patients received antimicrobial therapy for 27.1 weeks (IQR, 16.9-36.1), initially administrated intravenously in 59 patients $(89.4 \%)$ for 7.1 weeks (IQR, 4.9-11.7). All patients received a combined antistaphylococcal therapy during almost all treatment duration (25.6 weeks; IQR, 15.0-32.1). The antimicrobial were chosen according to recommendations and microbiological susceptibility testing in all cases, with respect of contraindications (i.e., drug interactions, previous adverse events ...). The main used molecules, doses and duration are presented in Table 2. Of note, 25 patients (37.9\%) received glycopeptides, given as initial empirical therapy ( $\mathrm{n}=4$; for a total duration $\leq 14$ days), a previous allergic reaction to other antistaphylococcal antibiotics $(n=12)$, a polymicrobial infection $(n=5)$, or difficult venous access ( $\mathrm{n}=4$, then using subcutaneous teicoplanin).

Treatment failure was observed in 16 cases (24.2\%) during a median follow-up period of 63.3 weeks (IQR, 44.7-103.1): i) 13 patients (19.7\%) with persistent infection including 9 patients requiring new surgery performed in a delay of 11.6 weeks (IQR, 5.3-25.6) after antimicrobial treatment initiation; ii) one relapse occurring 13.7 weeks after treatment disruption; and iii) 2 super-infections (one with Staphylococcus epidermidis, and one with Enterococcus faecalis and Streptococcus intermedius). Final evolution was favourable in 12 of the 16 patients with initial treatment failure. Three patients had to be amputated. Five patients (7.6\%) died during follow-up, without sepsis-related death. Of note, one fatal pulmonary embolism linked with prolonged bed rest occurred. At the end of follow-up, 24 patients (38.1\%) presented functional sequels, consisting in chronic pain and/or loss of function.

Patients presenting a treatment failure did not differ from those with favourable outcome regarding their baseline characteristics, with the exception of a higher prevalence of diabetes $(37.5 \%$ versus $10 \% ; \mathrm{p}=0.018)$ and a higher number of patients presenting a modified Charlson comorbidity index $>2$ ( $75.0 \%$ versus $44.0 \% ; \mathrm{p}=0.044)$. There was no difference between the two groups regarding the use of the main administered antimicrobials (Table 2). 
Table 1 Patient's characteristics and risk factors for native methicillin-susceptible Staphylococcus aureus bone and joint infection treatment failure

\begin{tabular}{|c|c|c|c|c|c|c|}
\hline \multirow[t]{2}{*}{ Risk factor for treatment failure } & \multirow[t]{2}{*}{ Total $(n=66)$} & \multirow{2}{*}{$\begin{array}{l}\text { Treatment failure } \\
(n=16)\end{array}$} & \multirow{2}{*}{$\begin{array}{l}\text { Favourable } \\
\text { outcome }(n=50)\end{array}$} & \multirow[t]{2}{*}{$p$} & \multicolumn{2}{|c|}{ Univariate analysis } \\
\hline & & & & & OR $(95 \% \mathrm{Cl})$ & $\mathbf{p}$ \\
\hline \multicolumn{7}{|l|}{ Demographic characteristics } \\
\hline Sex (male) & $42(63.6 \%)$ & $10(62.5 \%)$ & $32(64.0 \%)$ & 0.913 & $0.938(0.292-3.006)$ & 0.938 \\
\hline Age (years) & $61.2(45.9-71.9)$ & $61.2(48.5-69.6)$ & $60.4(43.5-76.5)$ & 0.828 & $1.119(0.820-1.525)^{*}$ & 0.479 \\
\hline \multicolumn{7}{|l|}{ Comorbidity } \\
\hline Modified Charlson score & $3.0(0.0-5.0)$ & $4.0(2.5-5.0)$ & $2.0(0.0-4.0)$ & 0.163 & $1.093(0.907-1.318)$ & 0.351 \\
\hline Modified Charlson score $>2$ & $34(51.5 \%)$ & $12(75.0 \%)$ & $22(44.0 \%)$ & 0.044 & $3.818(1.081-13.486)$ & 0.037 \\
\hline Obesity (BMI > 30 kg/m²) & $13(20.0 \%)$ & $3(20.0 \%)$ & $10(20.0 \%)$ & 1.000 & $1.000(0.236-4.231)$ & 1.000 \\
\hline Denutrition $(\mathrm{BMI}<18$ kg/m²) & $3(4.6 \%)$ & $1(6.7 \%)$ & $2(4.0 \%)$ & 1.000 & $1.714(0.145-20.332)$ & 0.669 \\
\hline Diabetes & $11(16.7 \%)$ & $6(37.5 \%)$ & $5(10.0 \%)$ & 0.018 & $5.400(1.372-21.260)$ & 0.016 \\
\hline Immunodepression & $8(12.1 \%)$ & $3(18.8 \%)$ & $5(10.0 \%)$ & 0.390 & 2.077 (0.437-9.871) & 0.358 \\
\hline Nephropathy & $10(15.2 \%)$ & $3(18.8 \%)$ & $7(14.0 \%)$ & 0.695 & $1.418(0.320-6.277)$ & 0.646 \\
\hline Hepatopathy & $2(3.0 \%)$ & $2(12.5 \%)$ & $0(0 \%)$ & 0.056 & NC & NC \\
\hline Chronic pulmonary disease & $12(18.2 \%)$ & $4(25.0 \%)$ & $8(16.0 \%)$ & 0.465 & $1.750(0.449-6.825)$ & 0.420 \\
\hline Chronic heart failure & $5(7.6 \%)$ & $0(0 \%)$ & $5(10.0 \%)$ & 0.325 & NC & NC \\
\hline Chronic inflammatory disease & $7(10.6 \%)$ & $2(12.5 \%)$ & $5(10.0 \%)$ & 1.000 & $1.286(0.224-7.370)$ & 0.778 \\
\hline Neoplasm, hemopathy & $7(10.6 \%)$ & $1(6.3 \%)$ & $6(12.0 \%)$ & 0.674 & $0.489(0.054-4.397)$ & 0.523 \\
\hline Dementia & $1(1.5 \%)$ & $1(6.3 \%)$ & $0(0 \%)$ & 0.242 & NC & NC \\
\hline \multicolumn{7}{|l|}{ BJl type } \\
\hline Arthritis & $15(22.7 \%)$ & $3(18.8 \%)$ & $12(24.0 \%)$ & 0.747 & $0.731(0.178-3.003)$ & 0.731 \\
\hline Osteomyelitis & $19(28.8 \%)$ & $8(50.0 \%)$ & $11(22.0 \%)$ & 0.054 & $3.545(1.082-11.615)$ & 0.037 \\
\hline Vertebral osteomyelitis & $32(48.5 \%)$ & $5(31.3 \%)$ & $27(54.0 \%)$ & 0.195 & $0.387(0.117-1.279)$ & 0.120 \\
\hline \multicolumn{7}{|l|}{ BJl mechanism } \\
\hline Haematogenous & $40(60.6 \%)$ & $8(50.0 \%)$ & $32(64.0 \%)$ & 0.480 & $0.563(0.180-1.754)$ & 0.321 \\
\hline Inoculation & $22(33.3 \%)$ & $7(43.8 \%)$ & $15(30.0 \%)$ & 0.475 & $1.815(0.570-5.779)$ & 0.313 \\
\hline Contiguity & $4(6.1 \%)$ & $1(6.3 \%)$ & $3(6.0 \%)$ & 1.000 & $1.044(0.101-10.806)$ & 0.971 \\
\hline \multicolumn{7}{|l|}{ BJl diagnosis } \\
\hline Fever & $43(65.2 \%)$ & $10(62.5 \%)$ & $33(66.0 \%)$ & 1.000 & $0.859(0.267-2.764)$ & 0.798 \\
\hline Fistula & $18(27.3 \%)$ & $7(43.8 \%)$ & $11(22.0 \%)$ & 0.112 & $2.758(0.836-9.092)$ & 0.096 \\
\hline Abscess & $33(50.0 \%)$ & $7(43.8 \%)$ & $26(52.0 \%)$ & 0.775 & $0.718(0.231-2.229)$ & 0.566 \\
\hline Chronic BJI (evolution > 4 weeks) & $28(42.4 \%)$ & $8(50.0 \%)$ & $20(40.0 \%)$ & 0.680 & $1.500(0.484-4.651)$ & 0.483 \\
\hline Delay from symptoms to diagnosis (weeks) & $2.1(0.0-10.3)$ & $2.6(0.0-34.4)$ & $2.1(0.5-9.8)$ & 0.905 & $1.026(0.996-1.057)$ & 0.095 \\
\hline Polymicrobial BJI & $10(15.2 \%)$ & $3(18.8 \%)$ & $7(14.0 \%)$ & 0.695 & $1.418(0.320-6.277)$ & 0.646 \\
\hline Infective endocarditis & $4(6.1 \%)$ & $0(0 \%)$ & $4(8.0 \%)$ & 0.565 & NC & NC \\
\hline Biological inflammatory syndrome & $58(87.9 \%)$ & $16(100 \%)$ & $42(84.0 \%)$ & 0.183 & NC & NC \\
\hline Maximal CRP value (mg/L) & $152.7(52.0-317.8)$ & $145.0(75.3-317.3)$ & $154.7(52.0-325.9)$ & 0.994 & $1.000(0.996-1.004)$ & 0.931 \\
\hline Maximal WBC count value $\left(/ \mathrm{mm}^{3}\right)$ & $10,200(7,720-14,920)$ & $11,000(10,200-16,280)$ & $9,710(7,350-14,770)$ & 0.100 & $1.058(0.961-1.164)$ & 0.251 \\
\hline Maximal neutrophil count value $\left(/ \mathrm{mm}^{3}\right)$ & $7,600(5,200-11,970)$ & $9,300(6,740-13,470)$ & $7,380(5,200-11,400)$ & 0.292 & $1.056(0.957-1.165)$ & 0.277 \\
\hline Chronic sepsis on pathological examination & 9/21 (47.4\%) & $2 / 3(66.7 \%)$ & $7 / 16(43.8 \%)$ & 0.582 & $2.571(0.192-34.473)$ & 0.476 \\
\hline Surgical treatment & $37(56.1 \%)$ & $11(68.8 \%)$ & $26(52.0 \%)$ & 0.377 & $2.031(0.615-6.701)$ & 0.245 \\
\hline Delay from symptoms to surgery (days) & $3(0-12.5)$ & $0(0-9)$ & $4(0-12)$ & 0.402 & 0.999 (0.994-1.004) & 0.632 \\
\hline \multicolumn{7}{|l|}{ Antibiotic use } \\
\hline Delay from diagnosis to specialist referral (days) & $4.9(0.0-23.1)$ & $6.3(0.7-91.0)$ & $4.9(0.0-18.5)$ & 0.445 & $1.102(1.003-1.211)$ & 0.043 \\
\hline
\end{tabular}


Table 1 Patient's characteristics and risk factors for native methicillin-susceptible Staphylococcus aureus bone and joint infection treatment failure (Continued)

\begin{tabular}{|c|c|c|c|c|c|c|}
\hline i.v.treatment & $59(89.4 \%)$ & $13(81.3 \%)$ & $46(92.0 \%)$ & 0.347 & $0.377(0.075-1.901)$ & 0.237 \\
\hline i.v.treatment duration (weeks) & $7.1(4.9-11.7)$ & $9.1(5.3-16.4)$ & $7.0(4.6-9.4)$ & 0.297 & $1.037(0.986-1.091)$ & 0.156 \\
\hline Bitherapy & $66(100 \%)$ & $16(100 \%)$ & $50(100 \%)$ & 1.000 & NC & NC \\
\hline Bitherapy duration (weeks) & $25.6(15.0-32.1)$ & $27.0(17.4-38.5)$ & $25.1(15.1-31.1)$ & 0.533 & $1.016(0.983-1.050)$ & 0.345 \\
\hline Initial anti-staphylococcal bitherapy & $53(81.5 \%)$ & $12(75.0 \%)$ & $41(83.7 \%)$ & 0.719 & $0.585(0.150-2.285)$ & 0.441 \\
\hline Initial anti-MSSA bitherapy & $40(61.5 \%)$ & $8(50.0 \%)$ & $32(65.3 \%)$ & 0.480 & $0.531(0.169-1.666)$ & 0.278 \\
\hline \multicolumn{7}{|l|}{ Biological follow-up } \\
\hline 1 month CRP level & $13.0(3.6-36.0)$ & $13.3(7.4-70.4)$ & $11.0(3.2-31.9)$ & 0.296 & $1.006(0.994-1.018)$ & 0.315 \\
\hline Decrease in CRP level at 1 month $<50 \%$ & $9(13.8 \%)$ & $4(26.7 \%)$ & $5(10.0 \%)$ & 0.204 & $3.273(0.752-14.245)$ & 0.114 \\
\hline 1 month CRP level < $10 \mathrm{mg} / \mathrm{L}$ & $29(44.6 \%)$ & $5(33.3 \%)$ & $24(48.0 \%)$ & 0.377 & $0.542(0.162-1.814)$ & 0.320 \\
\hline
\end{tabular}

Results are presented as $\mathrm{n}$ (\%) for dichotomic variables compared using Chi-square or Fisher exact tests, and median (interquartile range) for continuous variables, compared using Mann-Whitney U-test. Risk factors for treatment failure were assessed using logistic binary regression.

*For a 10-year increase in age.

BJl, Bone and joint infection; Cl, Confidence interval; BMI, Body mass index; CRP, C-reactive protein; i.v., Intravenous; MSSA, Methicillin-susceptible Staphylococcus aureus; NC, Not calculable; OR, Odds ratio; WBC, White blood cells.

Table 2 Main antimicrobial used in the 66 included patients with native methicillin-susceptible Staphylococcus aureus native bone and joint infection

\begin{tabular}{|c|c|c|c|c|}
\hline & All patients $(n=66)$ & Treatment failure $(n=16)$ & Favorable outcome $(n=50)$ & $\mathbf{p}$ \\
\hline i.v anti-staphylococcal penicillin & $49(74.2 \%)$ & $11(68.8 \%)$ & $38(76.0 \%)$ & 0.743 \\
\hline Dose (mg/kg/day) & $144.6(133.3-169.0)$ & $141.2(133.3-150.0)$ & $144.9(133.6-172.7)$ & 0.606 \\
\hline Duration (weeks) & $6.0(3.0-8.0)$ & $6.7(4.1-12.2)$ & $5.2(2.7-7.4)$ & 0.250 \\
\hline Glycopeptides & $25(37.9 \%)$ & $7(43.8 \%)$ & $18(36.0 \%)$ & 0.768 \\
\hline Vancomycine, & $10(15.2 \%)$ & $1(6.3 \%)$ & $9(18.0 \%)$ & 0.430 \\
\hline Dose (mg/kg/day) & $26.0(20.3-30.5)$ & 25 & $27.0(19.2-31.3)$ & NC \\
\hline Teicoplanin & $22(33.3 \%)$ & $6(37.5 \%)$ & $16(32.0 \%)$ & 0.764 \\
\hline Dose (mg/kg/day) & $5.7(4.1-7.0)$ & $7.2(5.4-8.4)$ & $5.2(3.9-6.5)$ & 0.197 \\
\hline Duration & $3.4(2.6-7.6)$ & $3.4(1.9-16.1)$ & $3.9(2.8-6.7)$ & 0.832 \\
\hline Aminoglycosides & $38(57.6 \%)$ & $9(56.3 \%)$ & $29(58.0 \%)$ & 1.000 \\
\hline Rifampin & $36(54.5 \%)$ & $9(56.3 \%)$ & $27(54.0 \%)$ & 1.000 \\
\hline Dose (mg/kg/day) & $18.8(14.6-21.2)$ & $18.0(14.6-21.4)$ & $18.8(15.2-20.8)$ & 0.841 \\
\hline Duration (weeks) & $20.3(2.7-34.6)$ & $27.5(11.8-53.1)$ & $16.0(2.7-25.3)$ & 0.334 \\
\hline Fluoroquinolones & $62(93.9 \%)$ & 15 (93.8\%) & 47 (94.0\%) & 1.000 \\
\hline Ofloxacin dose (mg/kg/day) & $6.7(5.8-7.5)$ & $7.1(6.3-7.5)$ & $6.35(5.7-7.3)$ & 0.240 \\
\hline Duration (weeks) & $14.6(8.0-27.6)$ & $17.0(10.9-31.9)$ & $14.6(7.6-24.4)$ & 0.397 \\
\hline Macrolid group & $46(69.7 \%)$ & $10(62.5 \%)$ & $36(72.0 \%)$ & 0.538 \\
\hline Clindamycin & $17(25.8 \%)$ & $6(37.5 \%)$ & $11(22.0 \%)$ & 0.324 \\
\hline Pristinamycin & $33(50.0 \%)$ & $5(31.3 \%)$ & $28(56.0 \%)$ & 0.150 \\
\hline Linezolid & $6(9.1 \%)$ & $1(6.3 \%)$ & $5(10.0 \%)$ & 1.000 \\
\hline Fucidic acid & $4(6.1 \%)$ & $1(6.3 \%)$ & $3(6.0 \%)$ & 1.000 \\
\hline Fosfomycin & $13(19.7 \%)$ & $4(25.0 \%)$ & $9(18.0 \%)$ & 0.719 \\
\hline Cotrimoxazole & $2(3.0 \%)$ & $1(6.3 \%)$ & $1(2.0 \%)$ & 0.429 \\
\hline
\end{tabular}

i.v: intravenous.

Difference between the two groups were assessed using Chi-square test or Fisher exact test for dichotomic variables, and Mann-Whitney U-test for continuous variables. 
The delay from diagnosis to infectious disease specialist advice (i.e. first phone contact, consultation or hospitalization) tended to have been higher for patients with treatment failure (6.3 days; IQR, 0.7-91.0; $\mathrm{p}=0.445$ ), and especially for those with persistent infection (7.7 days; IQR, 0.4$161.0 ; \mathrm{p}=0.217)$ than for patients with favourable outcome. In univariate analysis, diabetes (Odd ratio [OR], 5.4; 95\% confidence interval [CI], 1.372-21.260; $\mathrm{p}=0.016$ ), osteomyelitis (OR, 3.545; 95\% CI, 1.082-11.615; $\mathrm{p}=0.037$ ), and a prolonged delay for infectious disease specialist referral (OR, 1.102; 95\% CI, 1.003-1.211; $\mathrm{p}=0.043$ ) were associated with treatment failure (Table 1, Figure 1). Noninteracting and clinically relevant factors included in the multivariate logistic regression model were a modified Charlson comorbidity index $>2$ (OR, 3.322; 95\% CI, 0.753-14.661; $\mathrm{p}=0.113)$, the existence of a sinus tract (OR,

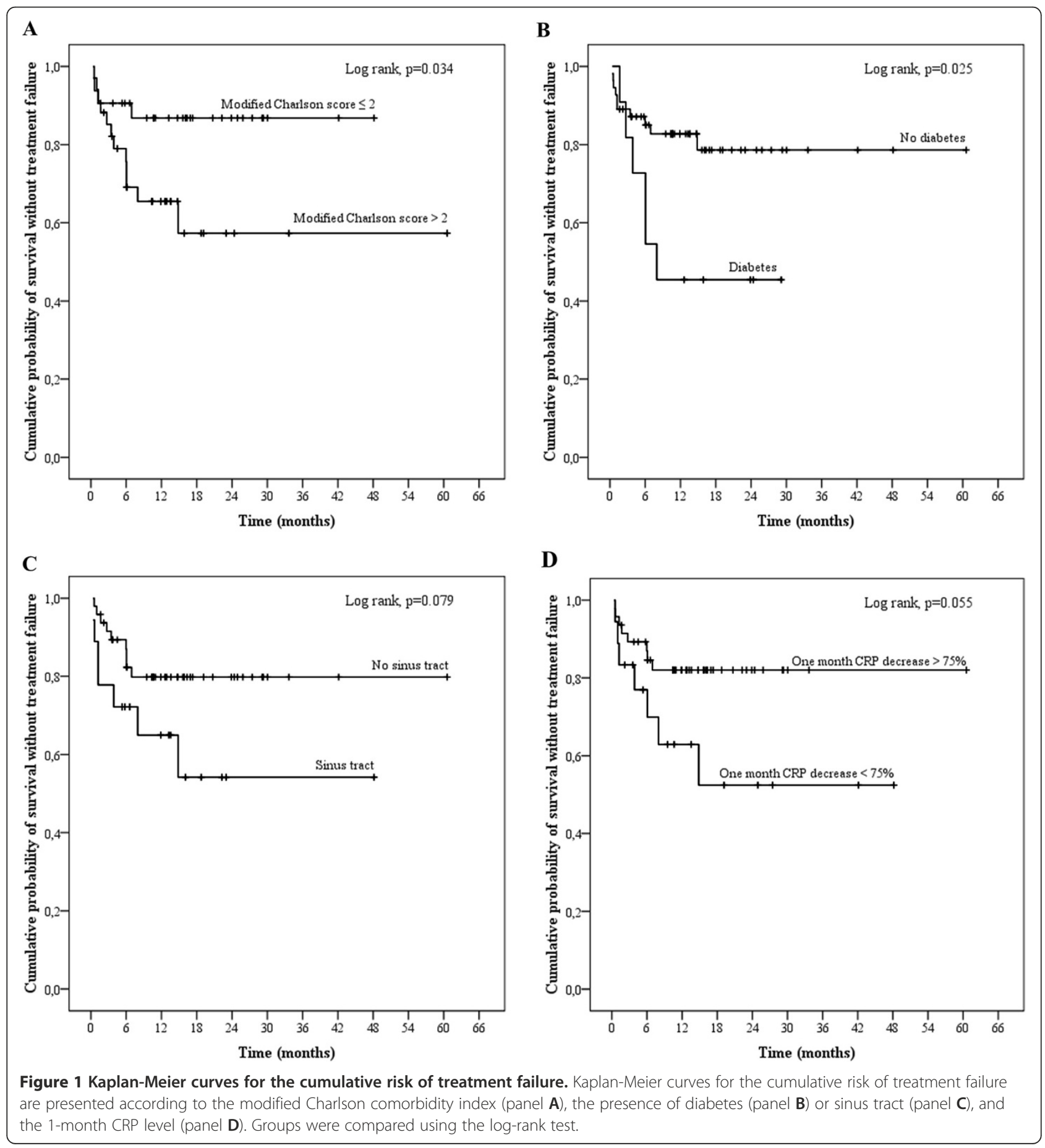


5.300; 95\% CI, 1.166-24.103; $\mathrm{p}=0.031$ ), a delayed referral to infectious disease specialist (OR, 1.134; 95\% CI, 1.013$1.271 ; \mathrm{p}=0.029)$, and a decreased in CRP level at 1 month $<75 \%$ (OR, 3.183; 95\% CI, 0.727-13.936; $\mathrm{p}=0.124$ ).

\section{Discussion}

In this retrospective cohort study including patients with native MSSA BJI, we pinpointed an important rate of unfavourable outcome, including a treatment failure rate reaching one quarter of patients and high proportion of functional sequels. These results should be interpreted in light of the high prevalence of difficult-to-treat infections enrolled in the study, due to the particular recruitment of our institution, a reference centre for the management of complex BJI. Moreover, the implication of $S$. aureus is known to be associated with a poorer outcome of native and device-associated septic arthritis [7-9]. However, these findings are consistent with the few available data in the literature $[2,10]$. Most of studies focusing on native staphylococcal BJI outcome were large epidemiologic investigations, based on national health surveillance programs, and consequently not design to assess precise outcome but only mortality. In a previous study, Wieland et al. disclosed a treatment failure rate of $12.2 \%$ among 41 native MSSA BJI [11]. Although these authors provided no detailed information about the type of patient recruitment, the short treatment court duration (43 days) and the low amount of patient requiring nursing home or rehabilitation facility (11\%) allow supposing that common forms of BJI were more represented. In our particular patient population requiring long-term antimicrobial therapy, independent risk factors for treatment were the presence of a sinus tract and a delayed referral to infectious disease specialist. Fistula has already been associated with poor outcome in prosthetic-joint infection and vertebral osteomyelitis [12,13]. Our findings confirmed that this clinical evidence for chronic infection is associated with treatment failure of native BJI. Diabetes was associated with a higher risk of treatment failure in univariate analysis but was excluded from the final model because the parameter was included in the Charlson comorbidity score calculation. However, it is a well-known risk factor for treatment failure [14]. Interestingly, we observed a trend in a higher treatment failure rate in bone infections (50.0\%) compared to arthritis (18.8\%). This difference probably lies in the higher rate of chronic infections, sinus tracts and abscesses among the osteomyelitis cases. Indeed, in the study by Wieland and colleagues, these two BJI types harboured the same outcome [11].

The impact of a referral to infectious disease specialist has been evaluated in several studies, which showed a benefit in terms of early adaptation of the initial empirical therapy after bacteriological results, and regarding dosages and duration of antimicrobials $[4,15]$. However, these series failed to highlight an improvement of BJI outcome. Nevertheless, Bauer and colleagues showed a decrease from 25 to $18 \%$ of treatment failure rate after the instauration of a weekly multidisciplinary staff meeting in their institution, even if this difference was not significant [15].

Some studies had found other determinants of poor outcome in native BJI, including advanced age, a raised white cell count at presentation, the presence of an abscess, a delayed initiation of antimicrobial treatment, a pre-existing joint disease which may delay diagnosis [9,13,16-18]. We failed to found any association between outcome and the nature of antimicrobial therapy, and especially with the use of glycopeptides used as empirical therapy, for polymicrobial infection, or in patients with beta-lactam allergy. Indeed, vancomycin therapy has been associated with a poor outcome in MSSA bacteraemia, due to its slow bactericidal activity $[19,20]$. One study including a majority of MSSA native osteomyelitis also suggested that vancomycin-treated infections were nearly three-times more likely to recur [21]. Contrary to prosthetic-joint infections, the use of rifampin did not appear as a protective factor in our study, possibly because of the less important implication of biofilm in absence of orthopaedic device. Finally, if the optimal treatment duration of BJI is unknown, a longer antimicrobial therapy did not appear as a protective factor. Prolonged antimicrobial therapy observed in our study is partly explained by the complicated nature of the included BJI. Another explanation lies in the retrospective nature of the study, which included patients in a 10-year period. Even in the absence of controlled randomized trial, the absence of evidence regarding the benefit of prolonged treatment lead to progressively decrease treatment duration in our population, without increasing failure rate over years (data not shown). Prospective controlled studies are needed to confirm the feasibility of shorter treatments. However, some studies had suggested that reducing treatment duration was associated with an increased risk of treatment failure, notably in vertebral osteomyelitis [22].

\section{Conclusions}

MSSA native BJI are associated with a high rate of treatment failure and sequel, despite the use of prolonged antimicrobial therapy. A multidisciplinary approach is required, with an early referral to infectious disease specialist, especially in debilitated patients or in presence of a sinus tract.

\section{Abbreviations}

BJI: Bone and joint infection; Cl: Confidence interval; IQR: Interquartile range; MRSA: Methicillin-resistant Staphylococcus aureus; MSSA: Methicillinsusceptible Staphylococcus aureus; OR: Odds ratio. 


\section{Competing interests}

This work was supported by the French Ministry of Health, the French Ministry of Education and the Institut National de la Santé et de la Recherche Médicale (INSERM). The funders had no role in study design, data collection and analysis, decision to publish, or preparation of the manuscript. There is no conflict of interest, for all authors.

\section{Authors' contributions}

FV participated in the design of the study and the acquisition and interpretation of data, performed the statistical analysis, and drafted the manuscript. $A B, J K$ and $S L$ participated in the acquisition and interpretation of data and helped to draft the manuscript. FA, FL and CC participated in the design of the study, and helped to statistical analysis and to draft the manuscript. TF conceived of the study, participated in its design and coordination, helped to statistical analysis and to draft the manuscript. All authors read and approved the final manuscript.

\section{Acknowledgements}

Lyon Bone and Joint Infection Study Group: Physicians - Florence Ader, François Biron, André Boibieux, Anissa Bouaziz, Evelyne Braun, Christian Chidiac, Fatiha Daoud, Tristan Ferry, Judith Karsenty, Johanna Lippman, Patrick Miailhes, Thomas Perpoint, Dominique Peyramond, Marie-Paule Vallat, Florent Valour; Surgeons - Cédric Barrey, Pierre Breton, Fabien Boucher, Romain Desmarchelier, Michel-Henry Fessy, Olivier Guyen, Christophe Lienhart, Sébastien Lustig, Alain-Ali Mojallal, Philippe Neyret, Franck Trouillet, Gualter Vaz; Microbiologists - Frédéric Laurent, Jean-Philippe Rasigade, François Vandenesch; Nuclear Medicine - Emmanuel Deshayes, Francesco Giammarile, Marc Janier, Isabelle Morelec; PK/PD specialists - Marie-Claude Gagnieu, Sylvain Goutelle, Michel Tod; Clinical Research Assistant - Marion Martinez

\section{Author details}

${ }^{1}$ Service des maladies infectieuses et tropicales, Hospices Civils de Lyon, Groupement Hospitalier Nord, Lyon, France. ${ }^{2}$ Université Claude Bernard Lyon 1, INSERM U1111, International Centre for Research in Infectious diseases, Lyon, France. ${ }^{3}$ Chirurgie orthopédique, Hospices Civils de Lyon, Groupement Hospitalier Nord, Lyon, France. ${ }^{4}$ Laboratoire de bactériologie, Centre National de Référence des Staphylocoques, Hospices Civils de Lyon, Lyon, France.

Received: 5 April 2014 Accepted: 12 August 2014

Published: 16 August 2014

\section{References}

1. Grammatico-Guillon L, Baron S, Gettner S, Lecuyer Al, Gaborit C, Rosset P, Rusch $E$, Bernard L: Bone and joint infections in hospitalized patients in France, 2008: clinical and economic outcomes. J Hosp Infect 2012, 82:40-48.

2. Garcia-Arias M, Balsa A, Mola EM: Septic arthritis. Best Pract Res Clin Rheumatol 2011, 25:407-421.

3. Mathews CJ, Weston VC, Jones A, Field M, Coakley G: Bacterial septic arthritis in adults. Lancet 2010, 375:846-855

4. Uckay I, Vernaz-Hegi N, Harbarth S, Stern R, Legout L, Vauthey L, Ferry T, Lübbeke A, Assal M, Lew D, Hoffmeyer P, Bernard L: Activity and impact on antibiotic use and costs of a dedicated infectious diseases consultant on a septic orthopaedic unit. J Infect 2009, 58:205-212

5. Tsukayama DT, Estrada R, Gustilo RB: Infection after total hip arthroplasty. A study of the treatment of one hundred and six infections. J Bone Joint Surg Am 1996, 78:512-523.

6. Charlson M, Szatrowski TP, Peterson J, Gold J: Validation of a combined comorbidity index. J Clin Epidemiol 1994, 47:1245-1251.

7. Azzam KA, Seeley M, Ghanem E, Austin MS, Purtill JJ, Parvizi J: Irrigation and debridement in the management of prosthetic joint infection: traditional indications revisited. J Arthroplasty 2010, 25:1022-1027.

8. Byren I, Bejon P, Atkins BL, Angus B, Masters S, McLardy-Smith P, Gundle R, Berendt $A$ : One hundred and twelve infected arthroplasties treated with 'DAIR' (debridement, antibiotics and implant retention): antibiotic duration and outcome. J Antimicrob Chemother 2009, 63:1264-1271.

9. Dubost JJ, Fis I, Denis P, Lopitaux R, Soubrier M, Ristori JM, Bussiere JL, Sirot J, Sauvezie B: Polyarticular septic arthritis. Medicine (Baltimore) 1993, 72:296-310.

10. Weston VC, Jones AC, Bradbury N, Fawthrop F, Doherty M: Clinical features and outcome of septic arthritis in a single UK Health District 1982-1991. Ann Rheum Dis 1999, 58:214-219.
11. Wieland BW, Marcantoni JR, Bommarito KM, Warren DK, Marschall J: A retrospective comparison of cetriaxone versus oxacillin for osteoarticular infections due to methicillin-susceptible Staphylococcus aureus. Clin infect Dis 2012, 54:585-590.

12. Marculescu CE, Berbari EF, Hanssen AD, Steckelberg JM, Harmsen SW, Mandrekar JN, Osmon DR: Outcome of prosthetic joint infections treated with debridement and retention of components. Clin Infect Dis 2006, 42:471-478.

13. McHenry MC, Easley KA, Locker GA: Vertebral osteomyelitis: long-term outcome for 253 patients from 7 Cleveland-area hospitals. Clin Infect Dis 2002, 34:1342-1350.

14. Gomez J, Rodriguez M, Banos V, Martinez L, Claver MA, Ruiz J, Simarro E, Canovas JA, Medina M, Clavel M: Orthopedic implant infection: prognostic factors and influence of long-term antibiotic treatment on evolution. Prospective study, 1992-1999. Enferm Infecc Microbiol Clin 2003, 21:232-236.

15. Bauer S, Bouldouyre MA, Oufella A, Palmari P, Bakir R, Fabreguettes A, Gros $\mathrm{H}$ : Impact of a multidisciplinary staff meeting on the quality of antibiotherapy prescription for bone and joint infections in orthopedic surgery. Med Mal Infect 2012, 42:603-607.

16. D'Agostino C, Scorzolini L, Massetti AP, Carnevalini M, d'Ettorre G, Venditti $M$, Vullo V, Orsi GB: A seven-year prospective study on spondylodiscitis: epidemiological and microbiological features. Infection 2010, 38:102-107.

17. Gupta MN, Sturrock RD, Field M: A prospective 2-year study of 75 patients with adult-onset septic arthritis. Rheumatology (Oxford) 2001, 40:24-30

18. Tarkowski A: Infection and musculoskeletal conditions: Infectious arthritis. Best Pract Res Clin Rheumatol 2006, 20:1029-1044.

19. Chang FY, Peacock JE Jr, Musher DM, Triplett P, MacDonald BB, Mylotte JM, O'Donnell A, Wagener MM, Yu VL: Staphylococcus aureus bacteremia: recurrence and the impact of antibiotic treatment in a prospective multicenter study. Medicine (Baltimore) 2003, 82:333-339.

20. Kim SH, Kim KH, Kim HB, Kim NJ, Kim EC, Oh MD, Choe KW: Outcome of vancomycin treatment in patients with methicillin-susceptible Staphylococcus aureus bacteremia. Antimicrob Agents Chemother 2008, 52:192-197.

21. Tice AD, Hoaglund PA, Shoultz DA: Risk factors and treatment outcomes in osteomyelitis. J Antimicrob Chemother 2003, 51:1261-1268.

22. Priest $\mathrm{DH}$, Peacock JE Jr: Hematogenous vertebral osteomyelitis due to Staphylococcus aureus in the adult: clinical features and therapeutic outcomes. South Med J 2005, 98:854-862.

doi:10.1186/1471-2334-14-443

Cite this article as: Valour et al.: Determinants of methicillin-susceptible Staphylococcus aureus native bone and joint infection treatment failure: a retrospective cohort study. BMC Infectious Diseases 2014 14:443.

\section{Submit your next manuscript to BioMed Central and take full advantage of:}

- Convenient online submission

- Thorough peer review

- No space constraints or color figure charges

- Immediate publication on acceptance

- Inclusion in PubMed, CAS, Scopus and Google Scholar

- Research which is freely available for redistribution 